\title{
Thermovaccination, thermoheliox as a stimulant of immune response. Kinetic model of process development
}

\author{
S. D. Varfolomeev, ${ }^{a, b}$ A. A. Panin, ${ }^{c}$ V. I. Bykov, ${ }^{b}$ and S. B. Tsybenova ${ }^{b^{\star}}$ \\ ${ }^{a}$ Institute of Physicochemical Foundations of the Functioning of \\ Neural Networks and Artificial Intelligence, M. V. Lomonosov Moscow State University, \\ Build. 11B, 1 Leninskie Gory, 119991 Moscow, Russian Federation. \\ Fax: +7 (499) 9393589 \\ ${ }^{b}$ N. M. Emanuel Institute of Biochemical Physics, Russian Academy of Sciences, \\ 4 ul. Kosygina, 119334 Moscow, Russian Federation. \\ Fax:+7 (499) 137 4101. E-mail: s.tsybenova@gmail.com \\ ${ }^{c}$ LLC MedTechInnovations, \\ 3-1 Blagoveshchenskii per., 123001 Moscow, Russian Federation
}

\begin{abstract}
A kinetic model is proposed to describe the key features of development of an acute viral infection, accumulation of antibodies, and immune response in the human body. The general features of immune system stimulation by thermoheliox are described. The model can be used for developing the basis for the application of thermoheliox in the treatment of patients affected by coronavirus.
\end{abstract}

Key words: acute viral infection, coronavirus, kinetic model, parametric analysis, therapy, thermoheliox, immune response.

Currently, the etiology of the development of the acute coronavirus infection is becoming clear. The development of the disease includes several stages.

- In the initial stage, infection gets into the body and the concentration of viruses increases. The incubation period may go without any visible clinical signs. If the immune system of the body is strong, the virus would not further develop. Otherwise, the immune system cannot fight off the virus, and penetration of the virus into host cells initiates the exponential growth of the concentration of viral particles and progression from mild to severe disease.

- The virus damages the host cells and dead cells are accumulated.

- Under intensely aerobic conditions, necrotic biochemical oxidation processes take place in the dead cells, e.g., lipid peroxidation, discharge of organic acids of the tricarboxylic acid cycle, ATP hydrolysis to phosphoric acid, and other acid-generating processes.

- Local acidification of the damaged area takes place.

- All enzymes containing the imidazole group of histidine ( $\left.K_{\mathrm{a}} \sim 7.0\right)$ in the active site, including key enzymes such as carbonic anhydrase and plasmin (plasminogen fibrinolytic system), stop working in the damaged area. The imidazole group of histidine present in the active sites of these enzymes is protonated as $\mathrm{pH}$ decreases (hydrogen ion concentration increases), and this blocks their catalytic activity. Thus, the damaged area no longer releases $\mathrm{CO}_{2}$ to the gas phase and accumulates bicarbonate ions.
- The microcirculatory vessels in the damaged area are thrombosed. The thrombus formation means that the plasminogen/plasmin system, which continuously dissolves the fibrin clots and thrombi in the body, is locally switched off. The switching-off of the plasminogen/plasmin system is of the same nature as the inactivation of carbonic anhydrase. The plasmin active site contains a histidine imidazole group, the protonation of which in the damaged area reversibly blocks the plasmin activity. Plasmin no longer hydrolyzes the fibrin clots, and a thrombus is formed.

Previously, ${ }^{1}$ we proposed and analyzed the kinetic model of development of an acute viral infection taking account of the exponential growth of concentrations of the infectious agent and pathogenic microflora, increasing acidity of the damaged area, and inactivation of the key enzymes of lung metabolism.

The developed model ${ }^{\mathbf{1}}$ qualitatively describes the infection phenomenon and development of the disease.

1. The first stage is the incubation period, in which almost no signs of the disease are observed.

2. At the end of the incubation period (induction period), fast symbiotrophic increase in the virus concentration and pathogenic microflora concentration with significant accumulation of the virus and microorganisms takes place.

3. In the primary periods of pathology development (incubation period and the start of active increase in the

Published in Russian in Izvestiya Akademii Nauk. Seriya Khimicheskaya, No. 9, pp. 1811-1815, September, 2020.

1066-5285/20/6909-1811 @ 2020 Springer Science+Business Media LLC 
concentrations of the virus and pathogenic microflora), the $\mathrm{pH}$ value in the damaged area is in the range of 7.2-7.4. In the absence of therapy or other deliberate influence on the system behavior, bifurcation growth and $\mathrm{pH}$-based inactivation of carbonic anhydrase take place. This should result in the full respiratory arrest. With the parameters that we chose (for details, see Ref. 1), the model predicts that respiratory arrest will occur on the 15 th or 16 th day after infection. The collapse is of the bifurcation nature, and the transition point is easily identified in the plot (Fig. 1). The bifurcation point is a crucially important characteristic of the process. This is the point of no return, actually, the time of death of the organism. When this point has been passed, the release of $\mathrm{CO}_{2}$ from the liquid phase to the gas phase is terminated. The uncontrolled increase in the bicarbonate concentration in blood takes place, i.e., respiration is fully blocked.

The model ${ }^{\mathbf{1}}$ is able to predict the system behavior when the virus is being eliminated and the growth of the pathogenic microflora is being suppressed by antibiotics. The key role of carbonic anhydrase, the enzyme clearing $\mathrm{CO}_{2}$ from lungs, was analyzed in detail. The possibilities for inhibition of the acid-generating processes of antioxidants and the therapeutic effects of high temperature were considered.

The natural development of the disease is associated with increasing body temperature. The inflammatory response is initiated by a large set of biochemical reactions, including the synthesis of inflammatory mediators of the prostaglandin type ${ }^{2,3}$ and heat shock proteins; this is accompanied by activation of the immune system.

Currently, thermoheliox (a thermolyzed mixture of helium and oxygen) is used highly efficiently for the treatment of patients affected by the coronavirus infection. The therapeutic procedure of using thermoheliox is to make the patient breathe with a mixture of helium and oxygen

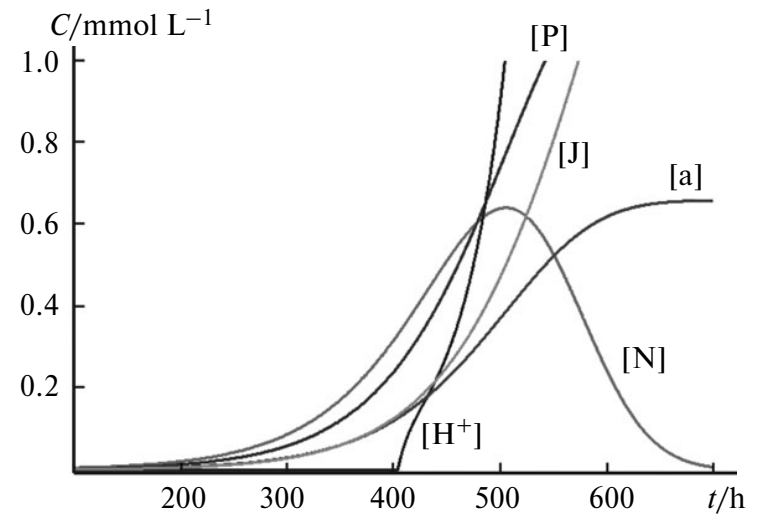

Fig. 1. Kinetics of the immune response: accumulation of antigen [a], antibodies $[\mathrm{J}]$, and kinetic variation of the amount of the virus $[\mathrm{N}]$ in the case of weak immune response; $\left[\mathrm{H}^{+}\right]$and $[\mathrm{P}]$ are concentrations of protons and dead acid-produced cells, respectively.
( $80-60 \%$ helium and $20-40 \%$ oxygen), with the gas mixture temperature being $50-90{ }^{\circ} \mathrm{C}$.

In our opinion, it is highly expedient to consider the potential of thermoheliox as not only a coronavirus inactivator, but also as an immune response initiator and stimulant within the framework of a single model (see Ref. 1). Helium, the major component of the heliumoxygen mixture of thermoheliox, possesses several unique physical properties, namely, high thermal conductivity, high heat capacity, molecular mobility, and penetrability into biological tissues.

One expected consequence of the application of thermoheliox heated to $70-90{ }^{\circ} \mathrm{C}$ is the thermal inactivation (thermal destruction) of viral particles. This means that destroyed protein-nucleic acid associates incapable of replication appear in the patient's blood. The higher the heliox temperature during the exposure, the more efficient the destruction of the virus and, hence, the higher the particle concentration. The inactivated virus and the protein components of the virus present in blood are actually natural antigens. According to the standard immune response program, the body should synthesize the antibodies. A local above-optimal temperature rise due to thermoheliox exposure enhances the expression of heat shock proteins, which are important for the immune response. The heat shock proteins enhance the adaptive immune response by transferring the antigen peptides to $\mathrm{T}$-lymphocytes. Thus, natural thermovaccination takes place. This is the natural protection of the body.

\section{Calculation methods}

The kinetic model is based on kinetic equations describing the growth and evolution of microbial and viral polulations. ${ }^{1}$ A system of ordinary differential equations was integrated using a specially developed program (in the Delphi Community Edition). Solution of the kinetic model makes it possible to visualize the variation dynamics of all variables and to study the system behavior upon the variation of system parameters.

\section{Results and Discussion}

Considering the processes of virus thermal degradation (N) and formation of antigen fragments (a), the increase in the concentration of the acid-produced dead cells $(\mathrm{P})$, the growth dynamics of pathogenic microflora $(\mathrm{M})$, and the change in the hydrogen ion concentration in the damaged area, the system of equations can be represented in the following form (the variables in this system of equations may reflect the concentration of a particular agent in the damaged area or the amount of this agent in the body):

$$
\begin{aligned}
& \mathrm{d}[\mathrm{N}] / \mathrm{d} t=k_{1}[\mathrm{~N}]-\alpha(T)[\mathrm{N}]-\xi[\mathrm{N}][\mathrm{J}], \\
& t=0,[\mathrm{~N}]=[\mathrm{N}]_{0},
\end{aligned}
$$




$$
\begin{aligned}
& \mathrm{d}[\mathrm{P}] / \mathrm{d} t=k_{2}[\mathrm{~N}], t=0,[\mathrm{P}]=0, \\
& \mathrm{~d}[\mathrm{M}] / \mathrm{d} t=\mu([\mathrm{P}])-\beta(T)[\mathrm{M}], \\
& \mu([\mathrm{P}])=\mu_{\mathrm{m}}[\mathrm{P}] /\left(K_{\mathrm{P}}+[\mathrm{P}]\right), t=0,[\mathrm{M}]=[\mathrm{M}]_{0}, \\
& \mathrm{~d}\left[\mathrm{H}^{+}\right] / \mathrm{d} t=\gamma\left(\left[\mathrm{H}^{+}\right]_{0}-\left[\mathrm{H}^{+}\right]\right)+\delta[\mathrm{M}]+\omega[\mathrm{P}]-v_{\mathrm{c}}, \\
& t=0,\left[\mathrm{H}^{+}\right]=\left[\mathrm{H}^{+}\right]_{0}, \\
& \mathrm{~d}[\mathrm{a}] / \mathrm{d} t=\alpha(T)[\mathrm{N}], t=0,[\mathrm{a}]=0, \\
& \mathrm{~d}[\mathrm{~J}] / \mathrm{d} t=\sigma[\mathrm{a}], t=0,[\mathrm{~J}]=0, \\
& v_{\mathrm{c}}=\frac{V_{\mathrm{m}}\left[\mathrm{HCO}_{3}^{-}\right]}{\left(1+\left[\mathrm{H}^{+}\right] / K_{\mathrm{a}}\right)\left(K_{\mathrm{m}}+\left[\mathrm{HCO}_{3}^{-}\right]\right)}=\frac{A}{1+\left[\mathrm{H}^{+}\right] / K_{\mathrm{a}}},
\end{aligned}
$$

where $[\mathrm{N}]$ is the concentration of the infecting virus in the damaged area; $k_{1}$ is the specific rate of virus replication in the body; $\alpha(T)$ is the parameter characterizing the rate of virus destruction due to the thermal inactivation; $[\mathrm{N}]_{0}$ is the initial infecting concentration of the virus; $\mu_{\mathrm{m}}$ is the maximum specific growth rate; $K_{\mathrm{P}}$ is the affinity of the pathogen to substrate $\mathrm{P}, \beta(T)$ is a parameter characterizing the thermal death of microorganisms. The coefficient $\delta$ is the productivity of microorganisms based on proton generation and the buffer properties of the blood system. The term $\gamma\left(\left[\mathrm{H}^{+}\right]_{0}-\left[\mathrm{H}^{+}\right]\right)$describes the "openness" of the system for protons, where $\left[\mathrm{H}^{+}\right]_{0}$ corresponds to the concentration of protons entering the damaged area, $\left[\mathrm{H}^{+}\right]$is the average proton concentration in the damaged area, and $\gamma$ is the mass transfer coefficient. The $v_{\mathrm{c}}$ value is the is the rate of the enzymatic reaction of carbonic anhydrase, i.e., the rate of hydroxyl ion generation by the carbonic anhydrase-catalyzed reaction. The parameter $\sigma$ corresponds to "maturing" of the immune response for $\sim 3$ days and amounts to $\sim 0.015 \mathrm{~h}^{-1}$. Apparently, the antigen (a) is formed via inactivation and destruction of viral particles. The maturing of the immune system with the formation of antibodies depends on the concentration [a]; the rate of virus destruction and elimination from the system depends on the antibody concentration $[\mathrm{J}]$ and the virus concentration (the term $-\xi[\mathrm{N}][\mathrm{J}]$ ). Qualitatively, it can be seen that for definite parameters $\alpha(T), \sigma$, and $\xi$ in Eq. (1), the negative terms would exceed $k_{1}$ and the virus will be eliminated.

The integration of the system of equations (1)-(7) results in solutions in which the concentration of the virus exponentially increases, reaches a maximum, and drops to zero (see Fig. 1). The calculations were carried out for the following parameters: $k_{1}=2 \cdot 10^{-2} \mathrm{~h}^{-1}, k_{2}=10^{-2} \mathrm{~h}^{-1}$, $\alpha=\delta=\omega=5 \cdot 10^{-3} \mathrm{~h}^{-1}, \beta=10^{-3} \mathrm{~h}^{-1}, \gamma=0.1 \mathrm{~h}^{-1}$, $\xi=0.03 \mathrm{~h}^{-1}, \sigma=0.015 \mathrm{~h}^{-1}, \mu_{\mathrm{m}}=2.5 \cdot 10^{-2} \mathrm{~mol} \mathrm{~L}^{-1} \mathrm{~h}^{-1}$, $K_{\mathrm{a}}=10^{-7.2} \mathrm{~mol} \mathrm{~L}^{-1}, K_{\mathrm{P}}=10^{-3} \mathrm{~mol} \mathrm{~L}^{-1}, A=5 \mathrm{~mol} \mathrm{~L}^{-1} \mathrm{~h}^{-1}$, $[\mathrm{N}](0)=[\mathrm{M}](0)=10^{-3} \mathrm{mmol} \mathrm{L}^{-1},[\mathrm{P}](0)=[\mathrm{a}](0)=$ $=[\mathrm{J}](0)=0 \mathrm{mmol} \mathrm{L}^{-1},\left[\mathrm{H}^{+}\right](0)=\left[\mathrm{H}^{+}\right]_{0}=10^{-7.44} \mathrm{~mol} \mathrm{~L}^{-1}$.
Figure 1 shows the calculation results for the case where the immune response is not sufficiently intense, and the collapse (bifurcation point) comes earlier than the immune response reaches the full strength. The recovery implies complete elimination of the virus $([\mathrm{N}]=0)$, an established invariable level of the number of damaged cells ([P]), and a high level of antibodies $([\mathrm{J}])$. It can be seen that the collapse (the curve of variation of $\left[\mathrm{H}^{+}\right]$) comes much earlier than the system overcomes the viral load. A favorable result can be attained if the immune response is intensified. Within the framework of our model, this means that, first of all, it is necessary to increase the antigen concentration (parameter $\alpha(T)$ ) and, perhaps, the efficiency of antibody synthesis.

The high body temperature during the development of acute inflammatory processes seems to have, at least, two consequences:

1) an elevated temperature is a physical factor promoting the thermal destruction of proteins and inactivation of the virus;

2) the appearance of inactivated viral particles and viral proteins in the blood is a classical factor for the development of immune response and for the synthesis of specific antibodies. In the traditional immunization approaches, the development of a vaccine is based on the use of "weakened", inactivated viral particles or proteins for injection into the body.

It is of interest to follow the effects of the virus thermal inactivation rate (parameter $\alpha(T)$ ), the rate of immune response maturing $(\sigma)$, and the rate of virus destruction $(\xi)$ on the immune response intensity.

The results of calculations of the antibody level $\mathbf{J}$ and the amount of the virus $\mathrm{N}$ upon variation of $\alpha(T)$ are depicted in Fig. 2.

The calculation results obtained upon variation of the parameters $\sigma$ (characteristic rate, time of activation of the immune system and the synthesis of antibodies) and $\xi$

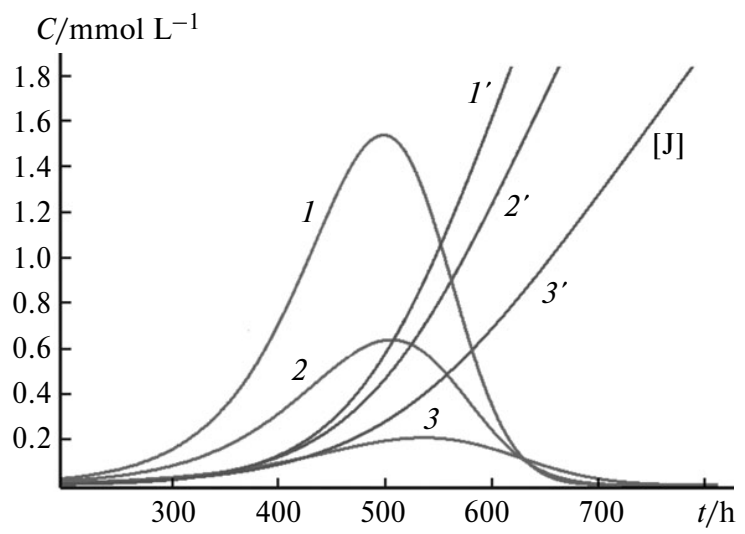

Fig. 2. Dynamics of variation of the virus concentration $[\mathrm{N}]$ $(1-3)$ and antibodies $[\mathrm{J}]\left(1^{\prime}-3^{\prime}\right)$ for the rate of virus destruction via thermal inactivation $\alpha(T)=0.003\left(1,1^{\prime}\right), 0.005\left(2,2^{\prime}\right)$, and $0.008 \mathrm{~h}^{-1}\left(3,3^{\prime}\right)$. 


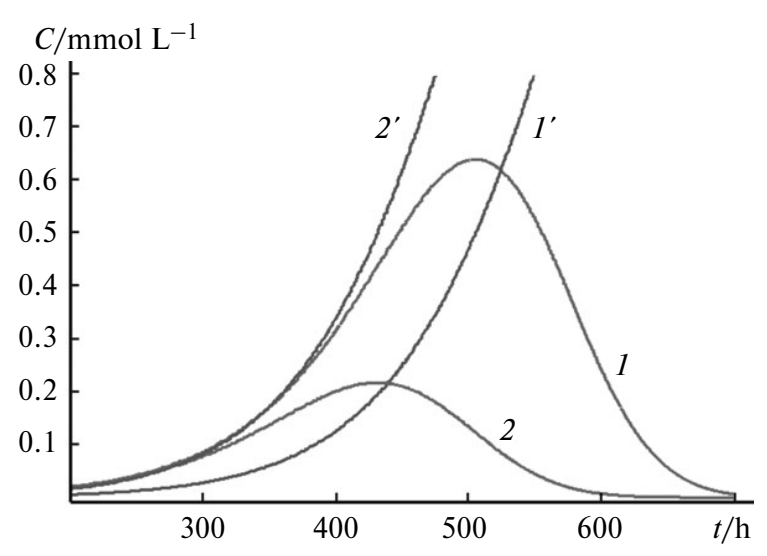

Fig. 3. Dynamics of variation of the virus concentration $[\mathrm{N}](1,2)$ and antibodies $[\mathrm{J}]\left(1^{\prime}, 2^{\prime}\right)$ for the immune system activation rate $\sigma=0.015\left(1,1^{\prime}\right)$ and $0.045 \mathrm{~h}^{-1}\left(2,2^{\prime}\right)$.

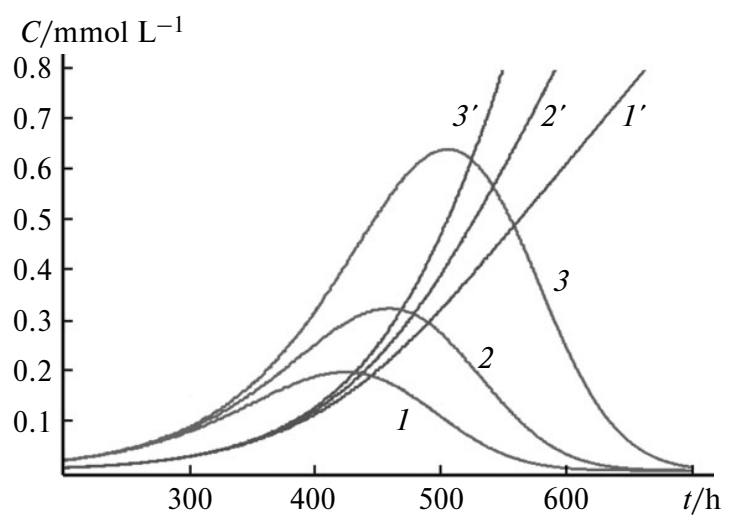

Fig. 4. Dynamics of variation of the virus concentration $[\mathrm{N}]$ $(1-3)$ and antibodies $[\mathrm{J}]\left(1^{\prime}-3^{\prime}\right)$ for the virus destruction rate $\xi=0.1\left(1,1^{\prime}\right), 0.06\left(2,2^{\prime}\right)$, and $0.03 \mathrm{~h}^{-1}\left(3,3^{\prime}\right)$.

(characteristic time of the virus destruction) are shown in Figs 3 and 4, respectively.

An important parameter that can be affected by an external heat field is $\alpha(T)$. As follows from the previous publication, ${ }^{1}$ on going from 36 to $41^{\circ} \mathrm{C}$, the parameter $\alpha(T)$ can increase by a factor of $2.8-3.5$. This activates the immune response upon the inflammatory increase in the patient's temperature (the therapeutic effect of elevated temperature).

More pronounced effects can be expected from the use of thermoheliox, a breathing mixture of oxygen and helium, at an elevated temperature of $55-90{ }^{\circ} \mathrm{C}$. The results of calculations with inclusion of the exposure to a temperature of $50-90{ }^{\circ} \mathrm{C}$ in the mechanism of pathology development are presented in Fig. 5.

Estimates demonstrate that on going from 36 to $60^{\circ} \mathrm{C}$, $\alpha(T)$ increases $10-15$-fold. With allowance for the signed multiplicity of a 30-min exposure of lungs to thermoheliox at a temperature of $70-90{ }^{\circ} \mathrm{C}$, the process is shown in Fig. 5, $b$ as a step in the antigen concentration. This sharply increases the rate of accumulation of antibodies $\mathbf{J}$ and significantly accelerates elimination of the virus. The plots in Figs 5, $a$ and $b$ differ in the time point of heliox application.

The designed equipment ${ }^{4}$ is able to measure and record the temperature of the breathing gas as it enters the patient's respiratory system. According to independent measurements, the exhaled gas temperature is $10-15^{\circ} \mathrm{C}$ lower. Thus, with the initial gas mixture temperature of $80^{\circ} \mathrm{C}$, the operating temperature of thermoheliox is in the range of $60-80^{\circ} \mathrm{C}$.

Theoretical analysis of the kinetic behavior of an organism infected with the coronavirus predicts a considerable activation of immune response at elevated temperature (the therapeutic effect of temperature rise) upon the action of high-temperature $\left(60-90^{\circ} \mathrm{C}\right)$ breathing mixture of oxygen and helium. The molecular basis of this stimulation is the thermal destruction of viral particles and increase in the concentration of destroyed proteins, which act as antigens for the synthesis of specific antibodies.
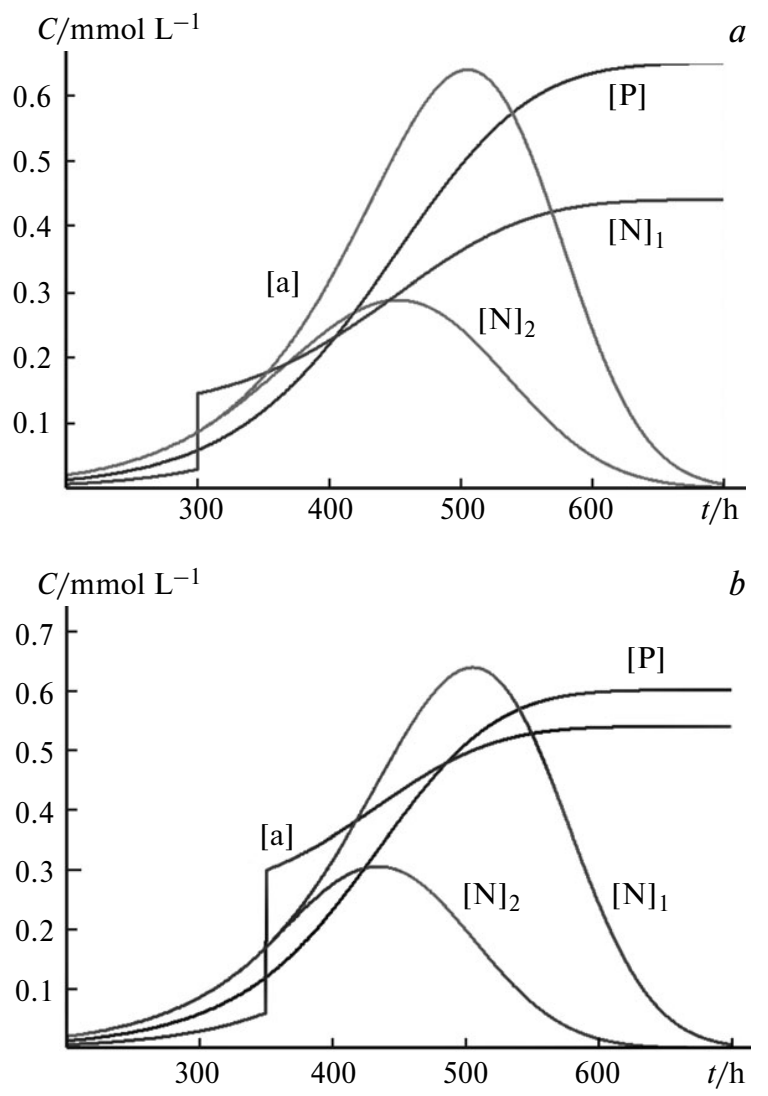

Fig. 5. Effect of thermoheliox on the development of the immune response and on the virus destruction dynamics, thermovaccination on the 12th $(a)$ and 15th $(b)$ day of infection. For comparison, variation dynamics of the virus concentration $\left([\mathrm{N}]_{1}\right)$ without the thermal action of thermoheliox is given (the same $[\mathrm{N}](t)$ curve as in Fig. 1), $[\mathrm{N}]_{2}$ is after thermovaccination. 
This paper describes the general principles of immune system stimulation by thermoheliox. The application of this method to a particular patient has personalized features. It appears important to monitor the general condition of the patient and oxygen saturation of blood, as a saturation of $97-99 \%$ should be attained. To this purpose, it is necessary to adjust a higher or lower oxygen content in heliox during every inhalation procedure. However, too high oxygen content in the helium-oxygen breathing mixture is inadmissible. Overexposure to oxygen may activate nonspecific oxidative processes, resulting in accumulation of acids in the damaged area. This method of vaccination is recommended for patients at the initial stage of infection and for patients with moderate severity of the disease and includes repeated 15-20 min exposures to thermoheliox at a temperature of $80-90^{\circ} \mathrm{C}$ with a rest period of 5-15 $\mathrm{min}$. This procedure appears reasonable on the basis of clinical experience: the above-listed conditions were most comfortable for patients.

These recommendations were applied to the treatment of coronavirus patients. Clinical trials of thermoheliox as a means for the treatment of the coronavirus infection were performed at the N. V. Sklifosovsky Research Institute of Emergency Medicine (Moscow). This hospital admits patients with 50-80\% damage of lungs. The clinical procedures were performed for dozens of patients; all of them recovered.

A fundamental benefit of the thermoheliox stimulation of the natural vaccination is the versatility of this approach and applicability to various viruses and pathogenic microorganisms.

The kinetic model considered here describes the key features of the development of acute viral infection in the human body, the dynamics of accumulation of antibodies, and immune response. Also, it forms the grounds for the use of thermoheliox in the treatment of patients affected by coronavirus and can help to outline the ways towards a new method for the treatment of viral diseases.

\section{References}

1. S. D. Varfolomeev, A. A. Panin, V. I. Bykov, S. B. Tsybenova, L. V. Shogenova, A. G. Chuchalin, Russ. Chem. Bull., 2020, 69, 1179.

2. S. D. Varfolomeev, A. T. Mevkh, Prostaglandiny - molekulyarnye bioregulyatory: biokinetika, biokhimiya, meditsina [Prostaglandins as Molecular Bioregulators: Biokinetics, Biochemistry, and Medicine], Izd-vo MGU, Moscow, 1985, 307 pp. (in Russian).

3. M. G. Sergeeva, A. T. Varfolomeeva, Kaskad arakhidonovoi kisloty [Arachidonic Acid Cascade], Narodnoe obrazovanie, Moscow, 2006, 256 pp. (in Russian).

4. Registration Certificate for the Medical Device RNZ 2016 3988. "Heliox Extreme" Apparatus: No. 10197: publ. 20.04.2016/ Applicant: LLC Medtekhinnovatsii (in Russian).

Received May 12, 2020; in revised form June 5, 2020; accepted June 10, 2020 